\title{
A Study on Impact of Covid-19 Over Employee Mental Wellness
}

\section{Dr. Ankita Saxena ${ }^{a}$}

\author{
${ }^{a}$ Assistant Professor, GLA University, Mathura, India. E-mail: ankitaaecsaxena@gmail.com
}

Article History: Received: 11 January 2021; Accepted: 27 February 2021; Published online: 5 April 2021

\begin{abstract}
Due to the current unprecedented catastrophe situation, the entire world is struggling hard not only in terms of physical health but in terms of mental wellness too. The people are surrounded by various uncertainties. The present time is giving rise to various distress like anxiety, depression, mental burnout. With the help of conceptual study, we analyzed the influence of present epidemic condition on employee psychological wellness. By drawing certain stressors like unemployment, job cuts, isolation, financial worries, zoom fatigue, panic buying, we measured the impact on mental well-being logically by critically examining the available literature. The search for articles was made in Google scholar, Web of Science scholar. Further, the study reveals that individuals are such a lot of terrified of getting COVID-19 that they are even ending up their life because of panic stigma or due to socio-economic reasons. Finally, we have proposed that how the role of HRM can be used as a way of handling such problem by introducing various organizational initiatives like building a strong emotional and psychological connect with their employees, providing word of assurance to curtail the hitches which employees are facing.
\end{abstract}

Keywords: Mental Health, Stressors, Distress, HRM Perspective.

\section{Introduction}

The world is countering exceptional wellbeing disaster yet it isn't the main occasion. Epidemic of COVID-19 is on an unprecedented scale. It has shaken the entire world and made overall furor. The healing estimates like communal separating and lockdown has completely upset our normal life exercises. Family work, thorough and never ending office work from home made life more confounded genuinely just as psychologically and emotionally upsetting.

Today, telecommute with advanced methods is the very crucial. The unexpected move in the work design made the things trying for employees physically and psychologically. These days the employees have various battles in their standard work life. Because of the far off working conditions, the representatives are feeling desolate and segregated. As they are not interfacing eye to eye with their chief and partners, the representatives feel baffled and disillusioned. In present occasions, the employees need to finish their errand alongside the extra home duties and vulnerabilities which obscured the scarcely discernible difference between work life and individual life. (Deloitte 2020).

Before COVID-19 and the lockdown circumstance, the employees were shuffling between adjusting their professional and individual life. Despite the fact that the lockdown circumstance has allowed to spent time with their relatives and yet without any homegrown assistance, individuals will undoubtedly play out the family unit work by their own which is very testing.

The current circumstance isn't just influencing the actual soundness of workers yet it has an unfavorable effect over emotional wellness as well. As individuals are confined in their homes since it is the best way to stay shielded from this irresistible sickness. Individuals are encircled by different vulnerabilities and dangers which is at last influencing their psychological wellness (WHO, 2020). The current pandemic circumstance has seriously hit the different parts of organizations and economy (Mac Intyrea, 2020; Shigemura et al., 2020). Unquestionably, apparently during a pandemic erupt, especially by virtue of a dark new contamination, individuals' passionate prosperity issues can at times be by and large dismissed. We are continually tallying the misfortunes endured by the nation's economy. In any case, the most overlooked part is the emotional wellness of workers which are really maintaining the business tasks and economy of a nation and they are treated as "human resources". In present circumstance, employee involvement ought to be a conspicuous worry for each association. Keeping the representatives' resolve high, and to keep up the degree of efficiency, is a very testing task for each business. As the workers are battling with their psychological status, representatives' emotional well-being ought to involve worry for each association.

Shockingly restricted examinations were led over the state of worker emotional well-being, as everyone is worried for the insights related with economy. The present theoretical investigation attempts to fill the hole and endeavor to investigate the fundamental stressors for working network and business. Further it additionally 
clarifies the results of stressors which are in the structure of misery and to assess the authoritative endeavors from human asset the executive's viewpoint which can limit the glitches looked by workers.

\section{Framework of the Study}

In current circumstance, the whole world in under danger. Such cataclysmic circumstance is offering ascend to numerous vulnerabilities. The entire world is battling, different nations to secure their residents have confined travel, schools, colleges, film corridors, eateries have been shut and other public social occasion occasions are on a stop. To diminish the degree of contamination and forestall themselves and their relatives, individuals have isolated themselves in their home. Individuals fear such strange exercises around them. The pandemic has seriously influenced the world's economy just as the psychological health of workers. Through the paper, we examined the effect of current pandemic circumstance on worker emotional well-being by investigating the different stressors which may results into the pain and further how the issue can be dealt with from HRM viewpoint to relieve the impact of COVID-19 over representatives' psychological wellbeing. Following fig. 1 is the connected diagram.

\section{STRESSORS}

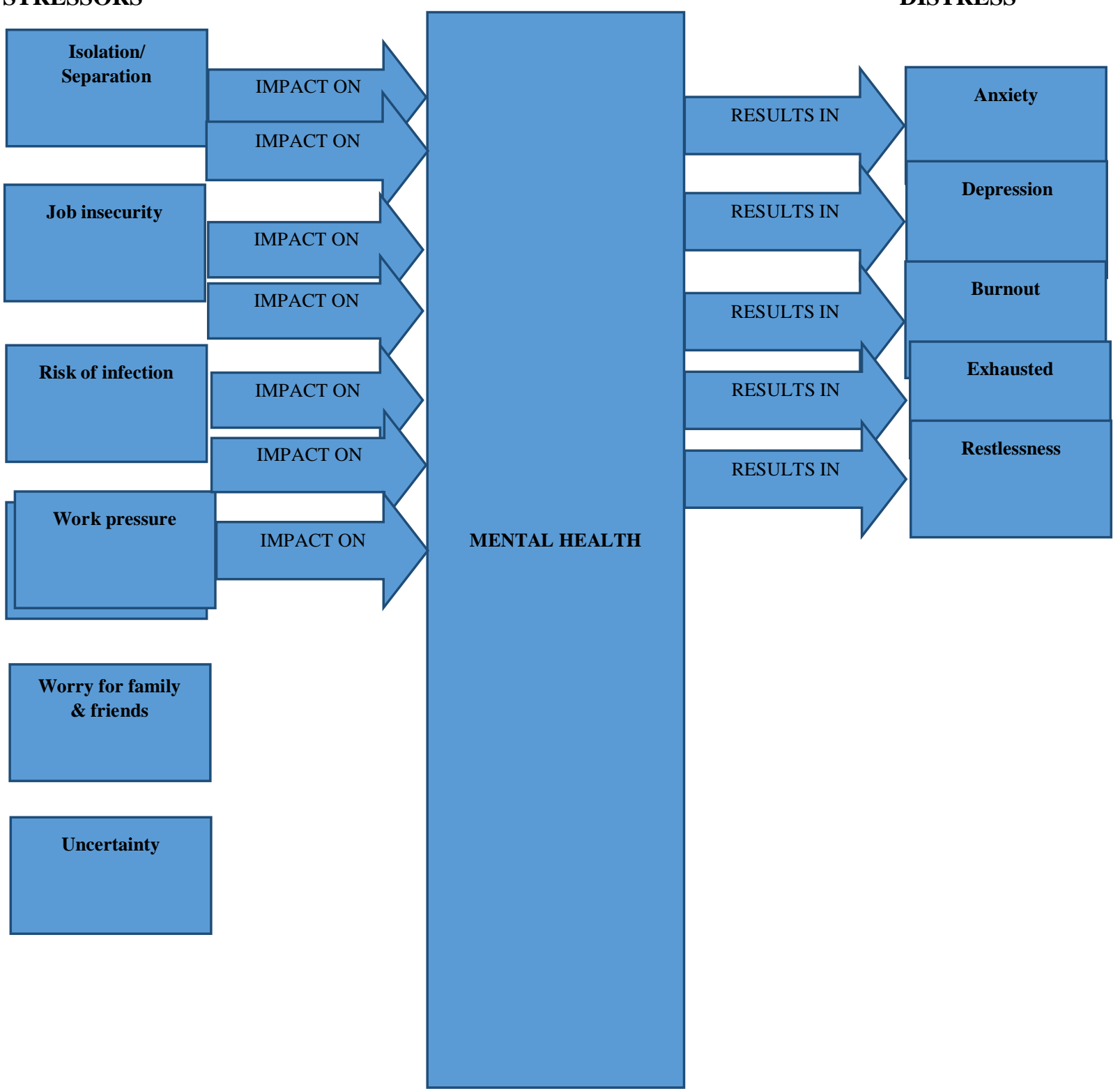

Fig. 1. Conceptual Framework

\section{Literature Review}

\section{Major Stressors \& Distress}


An intensive audit is directed with the assistance of later and current writing from different sources like government regulations, the rules gave by WHO by utilizing keywords like COVID-19 effect, worker psychological wellness, burnout, uneasiness, melancholy. We have zeroed in on the articles distributed during Feb 2020 to July 2020. The recent writing attempted to overcome any barrier between epidemic, representative brain science and HRM viewpoint by distinguishing the different stressors among working network and the effect of stressors as mental misery with the help of existing writing. The article inspected the accompanying significant stress givers during COVID-19.

\section{Separation Resulting Into Restiveness}

Throughout the time of lockdown, a large number of the enormous associations will undoubtedly telecommute over advanced methods. A few associations made the arrangement of work from home model for the time being, few are as yet in selection stage. Yet, we should acknowledge that none of the association is all set 100percent work from home model. Despite the fact that by different computerized implies like video calling, virtual gathering stages, the organizations are making a decent attempt that their working may not get influenced by guaranteeing the representative contribution. Yet, we can't fail to remember that individuals are social animals. Individuals are utilized to of customized human touch, informal collaborators' social affairs as it gives a sensation of feeling of belongingness at working environment and makes an imprint of a piece of group. We are not prepared to receive such intense far off and detached office culture as it might prompt eagerness (Business Standard 2020).

Without local help, people will without a doubt do family tasks by their own. As there is no division between the working environment timings and individual timings, in fact workforce are not use to of new progressed telecommute culture which subsequently consumes extra period of employees to change.

\section{Official Burden Subsequent Into Exhaustion}

On account of the far away working situation, the workforce is feeling excused as their work obligation is being tended to as they are not really present at workplace. In such case, the workforce is working significantly harder to legitimize and show off their undertakings and commitment to the organization. The online exhaustion just as the current pandemic erupt moreover offered rise to freeze buying in light of questionable lockdown situation. Considering which a scarcely conspicuous contrast among work and home become fleecy which in this manner inciting huge degree of work pressure which is a critical clarification of delegate burnout (SHRM 2020). Following figure (Fig.2) related to data dictated by SHRM on workforce psychological thriving.

\section{To what extent have you felt the following?}

Agree Disagree

I felt burned out from my work.

I felt used up at the end of the workday.

I felt emotionally drained from my work

$39.5 \%$

\section{$45.0 \%$}

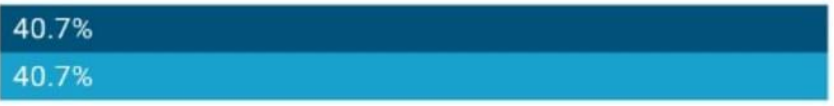

\section{$44.9 \%$}

$37.5 \%$

Chart: Employee Well-Being Study, Society for Human Resource Management (c) 2020

Fig.2. Employee Mental Well-being

\section{Job \& Financial Uncertainties Subsequent Into Depression}

Covid pandemic has hit scarcely the overall economy just as India. Affiliations are engaging and defying the financial crises as it is clearly influencing their wages, which are ceaselessly declining. Every affiliation needs to 
defy scaling back in coming $12 \mathrm{mths}$. (World Economic Forum, 2020). In such situation, the affiliations are left with no decision aside from to diminish the staff and executing substitute strategies for cost cutting like lay-offs, pay cuts and deferral in assessments. This is making a state of discouragement as the workforce has bundle of money related liabilities to the extent credits, EMIs and commitment and fear of occupation adversity, makes a condition of genuine financial crunches. Further, people can spectator the digestion of business openings around them on account of current pandemic condition happening into distress. Lakhs of salaried positions were lost in India in July, as indicated by most recent information delivered by the Center for Monitoring Indian Economy (CMIE).

\section{Risk of Infection \& Worry for Family and Friends Resulting Into Fear}

The representatives are in extraordinary concern that whether the associations can give work environment insurance. Indeed, even the individuals are such a lot of terrified of getting contaminated from COVID-19 that they are ending up their life.

\section{Uncertainty Resulting Into Anxiety}

No one knows for how long the pandemic flare-up influences the economy, regardless of whether we will have the option to get by from such tough situations both physically and monetarily. The dread from such unanswerable inquiries prompts vulnerability. Moreover, news inclusion of a pandemic flare-up may contain a measure of clashing data which can shake a person's trust (McCauley et al., 2013), makes disarray, vulnerability and expands the degree of despondency in the individual and their insufficiency to adapt to the power of the current circumstance. In addition, the absence of away from about the various degrees of dangers may lead people to envision the most noticeably awful, which compounds their tension (Desclaux et al., 2017).

\section{What Organizations Can Do}

In a particularly intense stage where workers are battling, bosses can assume a significant job in offering emotional and mental help. The business and workers both are responsible to limit and deal with the negative impact of COVID-19 flare-up.

\section{Use Technology for Support}

The associations should use the innovation in supporting the psychological prosperity of HR. Here the greatest test for assembling organizations lies in upgrading the personal time of the workers. For instance, these organizations' endeavors are exceptionally apparent as they changed such testing stage into promising circumstances by including them into developing their inclination as their sort of work didn't allow them to refresh themselves. The HR directors are likewise attempting to interface sincerely with their representatives by utilizing the advanced stage and directing on the web classes on actual wellness and online courses to remain mentally solid during the pandemic occasions what's more, the HR chiefs are additionally by organizing guiding meetings so they can uphold their workers in the midst of a ton of worry about losing their positions and fear of getting defiled (Goswami, 2020).

\section{Ensure Employees' Safety}

As workers are on edge for own just as relatives' wellbeing, associations need to comprehend their duty towards representatives. There are different area/organization where telecommute is beyond the realm of imagination, the representatives are coming at work environment by marking their wellbeing and life. Hence, it is the great obligation of organizations to deal with the workers' mental and actual wellbeing. For example, associations like Dr. Reddy's Laboratories, NSE, Fortis medical services are guaranteeing appropriate wellbeing measures at working environment and directing guiding meetings for their representatives to help them (Anand, 2020).

\section{Post Covid-19 Eras}

Individuals realize that the negative impacts of current pandemic flare-up can be dependable. The HR can assume a pivotal job in taking care of the delayed consequences of COVID-19 moreover. Numerous global organizations like Unilever, Deloitte trust in leading mentorship programs during pandemic circumstance to give profession direction and accomplishing singular objectives of workers in this way having more faithful 
representatives (Sharma, 2020). The HR chiefs are likewise centering over how the representatives can ricochet back at their work environment with full energy and excitement post COVID-19.

\section{What Employees Can Do}

\section{Emotional \& Mental Fitness}

It's a typical saying that on the off chance that you can't head outside, head inside. We as a whole are knowing that there is a great deal of cynicism everywhere through this period which is disturbing truly as well as intellectually and sincerely as well (Delloitte, 2020). In such circumstances contemplation and otherworldliness can assist the representatives with adapting up to the current testing time. Loosen up your body and soul through accomplishing inward harmony by investigating internal strength that helps in accomplishing passionate soundness. Infact this is the ideal opportunity to press an interruption fasten and unwind by edifying brain and soul. Take brief pauses and breath profound amidst working hours. Deal with your emotional wellness just as your environmental factors. A worry text can likewise do ponders for your partners.

\section{Stay Away from Destructive News}

Attempt to restrict the portion of related negative news over all stages like TV as news inclusion is giving inadequate and clashing data. Furthermore, web-based media likewise are the significant transporter of deluding data, it isn't generally a confided in wellspring of data for pandemic, accordingly make gossipy tidbits ((Bontcheva et al., 2013; Roth and Brönnimann, 2013). Spotlight more on the data identified with preventive measures and certainties of isolate as opposed to keeping a track on unpleasant information of expanding patients and death rate.

\section{Spare Quality Time with Family}

People are having adequate time with their kids by playing indoor games and remembering for the standard day activities of youngsters coming to fruition into better appreciation with them. People similarly got a chance to manage their people (The New Indian Express, May 2020).

\section{Focus on Physical Fitness}

Individuals typically escape to follow the timetable for actual wellness, now and again as a result of occupied work routine or family duties. This is the best time which can be used to deal with themselves. Enjoy some active work take a walk, take healthy eating regimen, take complete rest by finding some kind of harmony among individual and expert life. Build up a daily schedule for your work life.

\section{Conclusion}

The given examination is pioneer in the effect of Covid which uncovers generally speaking effect of Covid on human specifically to the working environment, which has quickly held the whole sphere. This article considers the different sources of tension, stress and frustration among the working local area in India the mental and biomedical examination relating to the emotional wellness, since the new examinations and patterns is by all accounts sitting above, the mental misfortune and issues because of pandemic. This review paper is a viable instrument for associations, human asset supervisors and concerned strategy producers to address the issues related with the psychological well-being of the employees. Since COVID-19 has deadened the life of employees in all the circles and this examination could demonstrate a distinct advantage in spurring and improving the spirits of employees.

\section{References}

1. Desclaux, A., Badji, D., Ndione, A.G., \& Sow, K. (2017). Accepted monitoring or endured quarantine? Ebola contacts' perceptions in Senegal. Social science \& medicine, 178, 38-45.

2. https://www.who.int/mental_health/in_the_workplace/en/

3. McCauley, M., Minsky, S., \& Viswanath, K. (2013). The H1N1 pandemic: media frames, stigmatization and coping. BMC Public Health, 13(1), 1-16.

4. Empowering practitioners to work differently Caring for employees' mental health during COVID-19. Deloitte, 2020. 
5. Rehman, U., Shahnawaz, M.G., Khan, N.H., Kharshiing, K.D., Khursheed, M., Gupta, K., \& Uniyal, R. (2021). Depression, anxiety and stress among Indians in times of Covid-19 lockdown. Community mental health journal, 57, 42-48. https://doi.org/10.1007/s10597-020-00664-x

6. Vyas, A., \& Gutta S. (2020) Modi govt, RBI, private sector, citizens: How India can be leader in fight against Covid-19. The Print.

7. Goswami A. (2020). Lockdown: Engaging downtime employees is equally important. HR Katha.

8. Vardhan, H., \& Sengupta, R. (2020). Covid-19: Policy Challenges and Traps in Restarting the Economy. Bloomberg Quint Opinion.

9. Anand, S. (2020). HR Is at the Front Line of India's Lockdown. Society for Human Resource Management.

10. Anand, S. (2020). HR Is at the Front Line of India's Lockdown. Society for Human Resource Management.

11. Lockdown side effects: Fear of job losses, salary cuts and delayed appraisals. PTI, 2020.

12. Hamouche S. (2020). COVID-19 \& Employees Mental Health: stressors, moderators and agenda for organizational actions.

13. Sharma, A. (2020). Looking at the workplace post lockdown. People matters.

14. Study suggests suicide as leading cause for over 300 deaths during lockdown in India. The Print PTI, 2020.

15. Gurchiek, K. (2020). COVID-19 Takes a Toll on Employees' Mental Well-Being. SHRM Research.

16. The New Indian Express Baska M. (2020) How are people teams responding to coronavirus?. Virgin Media. People Management.

17. Hayes, M., \& Curran, L.L.P. (2020). COVID-19 and Work Related Stress: Managing Mental Health of Remote Workers. Lexology.

18. Gopalan, H.S., \& Misra, A. (2020). COVID-19 pandemic and challenges for socio-economic issues, healthcare and national programs in India. Diabetes \& Metabolic Syndrome: Clinical Research \& Reviews, 14(5), 757-759. https://doi.org/10.1016/j.dsx.2020.05.041

19. Maria, N., Zaid, A., Catrin, S., Ahmed, K., Ahmed, A. J., Christos, I., \& Riaz, A. (2020). The socioeconomic implications of the coronavirus pandemic (COVID-19): A review. International Journal of Surgery, 78, 185-193. https://doi.org/10.1016/j.ijsu.2020.04.018

20. COVID-19 and Its Impact on Mental Health of Employees. India Employer Forum, 2020.

21. Suryanarayan, A. (2020) Employee retention is one of the most intense challenges faced by HR. HRWorld.com

22. Chandola, P. (2020). How HRs can make the employees stay positive during crisis. People matters.

23. Birla, N. (2020). How companies can maintain employee mental health in the time of Covid-1. Business Standard, Special on Coronavirus.

24. Rehman, U., Shahnawaz, M.G., Khan, N.H., Kharshiing, K.D., Khursheed, M., Gupta, K., \& Uniyal, R. (2020). Depression, anxiety and stress among Indians in times of Covid-19 lockdown. Community mental health journal, 1-7. 